\title{
Evaluation Selenocysteine Protective Effect in Carbon Disulfide Induced Hepatitis with a Mitochondrial Targeting Ratiometric Near- Infrared Fluorescent Probe
}

\author{
Xiaoyue Han, ${ }^{\dagger,}$ Rui Wang, ${ }^{\dagger}$ Xinyu Song, ${ }^{\dagger}$ Fabiao $\mathrm{Yu}^{*},{ }^{\dagger}{ }^{\circ}$ and Lingxin Chen ${ }^{*}, \S_{\odot}$ \\ ${ }^{\dagger}$ CAS Key Laboratory of Coastal Environmental Processes and Ecological Remediation, Research Centre for Coastal Environmental \\ Engineering and Technology, Yantai Institute of Coastal Zone Research, Chinese Academy of Sciences, Yantai 264003, China \\ ${ }^{\ddagger}$ University of Chinese Academy of Sciences, Beijing 100049, China \\ ${ }^{\S}$ College of Chemistry and Chemical Engineering, Yantai University, Yantai 264005, China
}

Supporting Information

\begin{abstract}
As important active sites of oxidoreductase in mitochondria, selenocysteine $(\mathrm{Sec})$ takes the responsibility for cytoprotective effect and intracellular redox homeostasis. Carbon disulfide $\left(\mathrm{CS}_{2}\right)$ is a common solvent in industry, which can inhibit the activities of oxidoreductase and induce oxidative stress. It is necessary to investigate the cytoprotective effect of Sec against $\mathrm{CS}_{2}$ exposure. After integrated, the response moiety 2,4-dinitrobenzenesulfonamide and mitochondrial targeting moiety into the near-infrared heptamethine cyanine fluorophore, we develop a mitochondrial targeting near-infrared ratiometric fluorescent probe Mito$\operatorname{diNO}_{2}$ for the selective and sensitive analysis of Sec concentration fluctuations in living cells and in mice models under the stimulation of $\mathrm{CS}_{2}$. The probe can effectively accumulate in mitochondria and selectively detect the endogenous Sec concentrations in BRL 3A, RH-35, HL-7702, HepG2, and SMMC-7721 cell lines. The results indicate that $\mathrm{CS}_{2}$ exposure can lead to a decrease of Sec level and result in mitochondrial related acute inflammation. The exogenous supplement of Sec can protect cells from oxidative damage and reduce the symptoms of inflammation. We also establish $\mathrm{CS}_{2}$ induced acute and chronic hepatitis mice models to examine the tissue toxicity of $\mathrm{CS}_{2}$ and cytoprotection of Sec in liver. The organism can increase the concentration of Sec to deal with the damage caused by $\mathrm{CS}_{2}$ in acute hepatitis mice model. Also the exogenous supplement of Sec for the two mice models can effectively defend the $\mathrm{CS}_{2}$ induced liver damage. The real-time imaging of Sec concentrations in liver can be used to assess the degrees of liver injury during $\mathrm{CS}_{2}$ poisoning. The above applications make our probe a potential candidate for the clinical accurate diagnosis and treatment of $\mathrm{CS}_{2}$ poisoning.
\end{abstract}

S elenium is a fascinating trace element which was initially described as a toxin and subsequently recognized as an essential element for health. ${ }^{1}$ Now the selenium containing species, including selenium-containing amino acids, selenium element, hydrogen selenide $\left(\mathrm{H}_{2} \mathrm{Se}\right)$, and selenoproteins ( $\left.\mathrm{SePs}\right)$, have been defined as reactive selenium species. ${ }^{2}$ Selenium benefits for protecting against inflammation and boosting the immune system functions. ${ }^{3}$ Its vital biological and biomedical functions are largely dependent on selenium-containing amino acids and selenoproteins. ${ }^{4}$ For examples, thioredoxin reductases (TrxR) play important antioxidant and redox regulatory roles in catalyzing the NADPH-dependent reduction of thioredoxin as well as other proteins. ${ }^{5}$ However, the active site of TrxR involved in the antioxidant reaction is selenocysteine $(\mathrm{Sec}) .{ }^{6}$ Moreover, Sec can regulate thyroid metabolism, maintain the cellular redox homeostasis, and protect the cell from oxidative damage. ${ }^{7}$ Therefore, Sec, which has been considered as the first-line against oxidative stress in cellular antioxidant defense system, plays an important role in protecting organism against oxidants and repairing oxidant induced damage to lipids, proteins, or DNA. ${ }^{8}$
Mitochondrion is the highly dynamic organelle in cells whose function is crucial for the maintenance of cellular redox homeostasis. ${ }^{9}$ Despite the protective efforts defended by antioxidant system, it is difficult to avoid oxidative damage caused by the uncontrolled generation of reactive oxygen species (ROS) in mitochondria, which leads to mitochondrial dysfunction, ${ }^{10}$ and finally results in a series of diseases, such as Alzheimer's disease, strokes, Parkinson's disease, transient ischemic attack, diabetes, hepatitis, and primary biliary cirrhosis. ${ }^{11}$ Therefore, to monitor mitochondrial redox state it is critical for researching the occurrence, development, and treatment of a series of diseases.

Carbon disulfide $\left(\mathrm{CS}_{2}\right)$ is a common organic solvent, which has been widely used in the fields of industry, agriculture, animal husbandry, and daily life. ${ }^{12} \mathrm{CS}_{2}$ can be easily absorbed through breathing and skin. ${ }^{13} \mathrm{CS}_{2}$ is a widespread enzyme inhibitor with

Received: March 23, 2018

Accepted: June 4, 2018

Published: June 4, 2018 
cytotoxic effects, which can disrupt the normal metabolism of cells and interfere cell signal transduction. The exposure of $\mathrm{CS}_{2}$ can lead to Parkinson's disease, atherosclerosis, coronary heart disease, hepatitis, and cirrhosis. ${ }^{12} \mathrm{CS}_{2}$ can react with the selenol group $(-\mathrm{SeH})$, which is the critical active sites of oxidoreductases. ${ }^{12}$ The inhibition of oxidoreductases will hinder the intracellular redox homeostasis and increase the abnormal level of ROS. The overproduced ROS can attack the unsaturated fatty acids in the biofilm and trigger the free radical chain reaction, which induces severe oxidative damage to major organelles and causes related diseases. ${ }^{14}$ Most of these oxidoreductases exist in mitochondria. However, the pathogenesis of $\mathrm{CS}_{2}$ poisoning in mitochondria is far from clear yet. Therefore, it is necessary to further study the toxicological role of $\mathrm{CS}_{2}$ in mitochondria. Given the potential relationship between $\mathrm{CS}_{2}$ and $\mathrm{Sec}$, we hypothesize that Sec can be utilized as a biomarker to evaluate redox level fluctuations upon $\mathrm{CS}_{2}$ treatment in living cell and in vivo.

The common methods to quantify Sec concentration basically include liquid chromatography, ${ }^{15}$ nuclear magnetic resonance spectrometry, ${ }^{16}$ and coupled plasma-mass spectrometry. ${ }^{17}$ Although these methods are precise for the detection of Sec, they usually require sample preparation and unable to achieve in real-time and in situ detection. Compared with these detection technologies, fluorescence imaging technology based on fluorescent probes have been widely used in bioimaging analysis of biological reactive species, benefiting from its advantages of highly sensitivity, excellent selectivity, less invasiveness, rapid response, as well as high spatial and temporal resolution. ${ }^{18-25}$ The fluorescent probes designed for the detection of Sec are dependent on (i) the nucleophilic substitution reaction of 2,4dinitrobenzenoxy, ${ }^{26,27} 2,4$-dinitrobenzenesulfonamide, ${ }^{28-34}$ and selenium-nitrogen bond; ${ }^{35}$ (ii) addition reaction of acrylate; ${ }^{36}$ (iii) as well as the selenium-sulfur exchange reaction. ${ }^{37}$ However, as far as we known, there is no probe targeting in mitochondria for the quantification and evaluation of Secprotective effect on $\mathrm{CS}_{2}$-induced acute/chronic hepatitis. For the propose of in vivo imaging, the near-infrared (NIR) fluorescent probe is desirable because the NIR fluorescence allows deep tissue penetration, decreases photodamage to the organism, and has low absorbance by intrinsic water, lipids, as well as heme of myoglobin and hemoglobin. ${ }^{38-40}$ The ratiometric analysis of the spectra at the two emission channels can effectively avoid interference induced by the excitation/emission efficiency and changeable element from inhomogeneity loading or uneven distribution of the probe as well as environmental states. ${ }^{41,42}$ For the design of a Sec probe, few ratiometric NIR fluorescent probes have been reported for the imaging of Sec in living cells and in vivo. ${ }^{37}$ Therefore, we want to develop a ratiometric NIR florescent probe for the sensitive and selective quantification of Sec level changes in mitochondria as well as evaluation the relationship between Sec levels and inflammation degrees in $\mathrm{CS}_{2}$ induced acute/chronic hepatitis.

Herein, we reported a NIR ratiometric fluorescent probe (Mito-diNO $\mathrm{N}_{2}$ ) for selective quantification of Sec concentration changes during mitochondria related inflammation and acute/ chronic hepatitis. The probe was composed of three moieties: heptamethine cyanine as the signal transduction unit, 2,4dinitrobenzenesulfonamide as the response unit, and lipophilic triphenylphosphonium cation $\left(\mathrm{PPh}_{3}{ }^{+}\right)$as mitochondrion targeting unit (Scheme 1). Mito-diNO $\mathrm{NO}_{2}$ could fast response to Sec within 4 min without disturbance caused by other reactive sulfur species (RSS). Also, the probe could effectively locate in mitochondria and sensitively analysis the endogenous Sec
Scheme 1. Molecular Structure of Mito- $\mathrm{diNO}_{2}$ and Its Proposed Response Mechanism Towards Selenocysteine

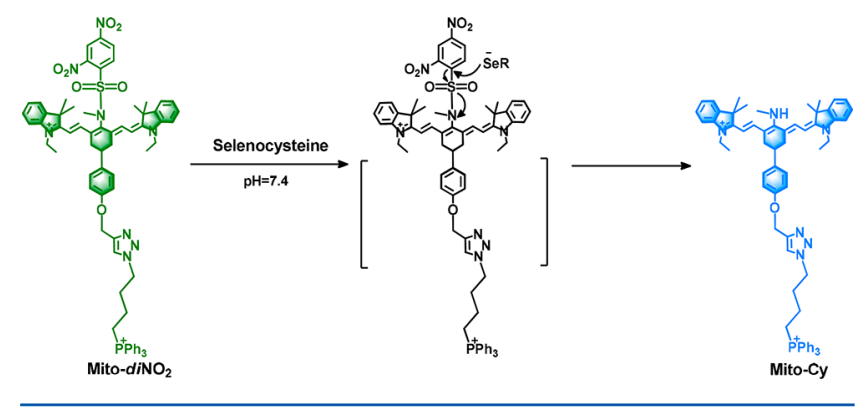

concentration fluctuations. Using Mito-diNO investigated the $\mathrm{Sec}$ protective effect in $\mathrm{CS}_{2}$ induced mitochondria related inflammation. Furthermore, we utilized Mito-diNO $\mathrm{N}_{2}$ to detect the Sec concentration changes in $\mathrm{CS}_{2}$ induced acute/chronic hepatitis stages and evaluate the relevance between $\mathrm{Sec}$ concentrations and $\mathrm{CS}_{2}$ induced organ damage degrees.

\section{EXPERIMENTAL SECTION}

Establishment of $\mathrm{CS}_{2}$ Induced Cell Models and Acute/ Chronic Hepatitis Mice Models. The mitochondrial related acute inflammation model was established by addition of $1 \mu \mathrm{M}$ $\mathrm{CS}_{2}$ for $6 \mathrm{~h}$ in SMMC-7721 cells. The acute hepatitis mice models were induced by intraperitoneal (i.p.) injection of $\mathrm{CS}_{2}$ $(0.6 \mathrm{~mL} / \mathrm{kg}, 50 \% \mathrm{v} / \mathrm{v}$ in liquid paraffin $)$ for $6,12,18$, and $24 \mathrm{~h}$, respectively. ${ }^{43}$ The chronic hepatitis mice models were established by inhaled $5 \% \mathrm{CS}_{2}$ (at air flow rate with $40 \mathrm{~mL} /$ min for $1 \mathrm{~h}, \mathrm{qd}$ ) for 1 month, 2 months, 3 months, and 4 months, respectively. The therapy groups of acute hepatitis mice were pretreated with $500 \mu \mathrm{g} / \mathrm{kg}(\mathrm{Sec})_{2}$ (i.p.) in PBS qd for 8 weeks before i.p. injection of $\mathrm{CS}_{2}$. The therapy groups of chronic hepatitis mice were pretreated with $500 \mu \mathrm{g} / \mathrm{kg}(\mathrm{Sec})_{2}$ (i.p.) in PBS qd for 8 weeks before the inhalation of $\mathrm{CS}_{2}$. And $500 \mu \mathrm{g} / \mathrm{kg}$ $(\mathrm{Sec})_{2}$ (i.p.) in PBS was continued to be given before the inhalation of $5 \% \mathrm{CS}_{2}$ (at air flow rate with $40 \mathrm{~mL} / \mathrm{min}$ for $1 \mathrm{~h}, \mathrm{qd}$ ) for 1 month, 2 months, 3 months, and 4 months, respectively.

Laser Scanning Confocal Imaging. Cell images in Figure 1, Figure $2 a$, and Figure $3 a$ were obtained through confocal laserscanning microscope (Olympus FV1000) with an objective lens being 60 or 40 . We selected $730 \mathrm{~nm}$ for channel 1 and $635 \mathrm{~nm}$ for channel 2 as the excitation wavelength, respectively. The living cells were plated on culture plate $(\Phi=20 \mathrm{~mm})$ for $24 \mathrm{~h}$ at $37^{\circ} \mathrm{C}$ in an atmosphere of $5 \% \mathrm{CO}_{2}$ and $95 \%$ air before imaging. The cells were incubated with probe Mito- $\mathrm{diNO}_{2}(10 \mu \mathrm{M})$ in the culture plates which were filled with fresh complete medium ( 1 $\mathrm{mL}$ ) before imaging.

Flow Cytometry Analysis. The cells were cultured at $2.0 \times$ $10^{5}$ cells/well in 6-well plates and then treated with probes as described in the paper. After harvest, cells were washed and suspended in fresh complete medium and analyzed by flow cytometry. For channel 1, the excitation wavelength was selected $730 \mathrm{~nm}$ and the collected wavelengths were selected 750-810 nm. For channel 2, the excitation wavelength was selected 633 $\mathrm{nm}$ and the collected wavelengths were selected $650-670 \mathrm{~nm}$.

In Vivo Imaging. C57BL/6 mice were kept in equal light/ dark and were free to water and food. A PerkinElmer IVIS Lumina XR Series III system was utilized for in vivo imaging. Before imaging, the probe Mito-diNO $(10 \mu \mathrm{M}, 50 \mu \mathrm{L}$, in 1:99 $\mathrm{DMSO} /$ saline, $\mathrm{v} / \mathrm{v}$ ) was injected through the portal vein into 


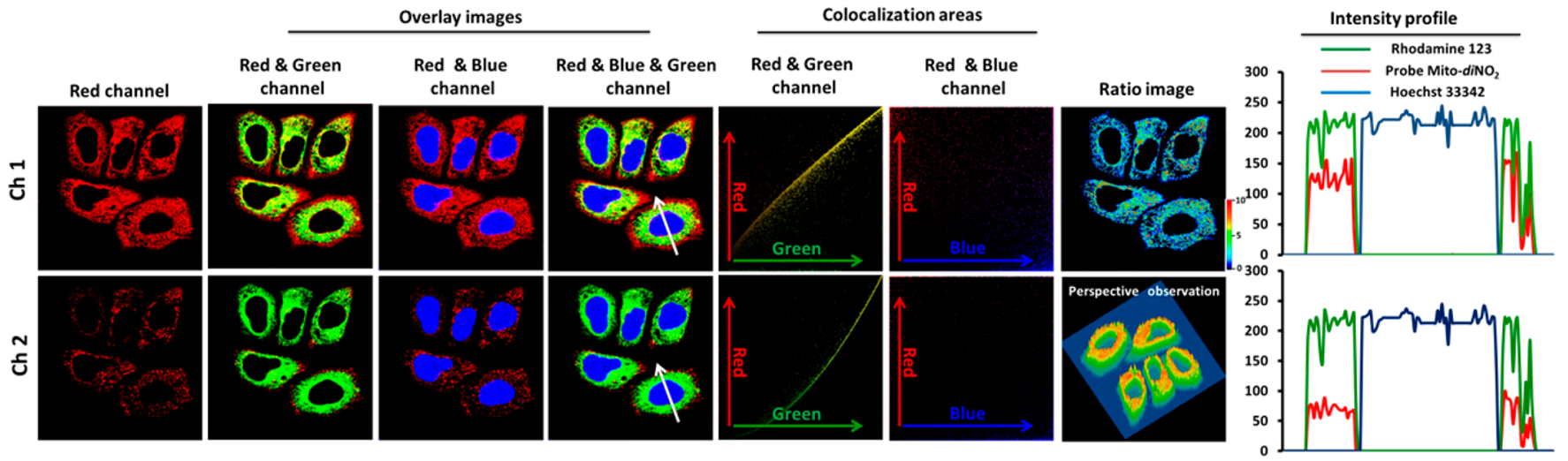

Figure 1. Intracellular localization of Mito-diNO $\mathrm{N}_{2}$ in HeLa cells. All the tested cells were prestained with Hochest $33342(1 \mu \mathrm{g} / \mathrm{mL}, 30 \mathrm{~min})$, Rhodamine $123(1 \mu \mathrm{g} / \mathrm{mL}, 15 \mathrm{~min})$, and Mito-diNO $\mathrm{NO}_{2}(10 \mu \mathrm{M}, 2 \mathrm{~min})$ at $37^{\circ} \mathrm{C}$ before imaging.

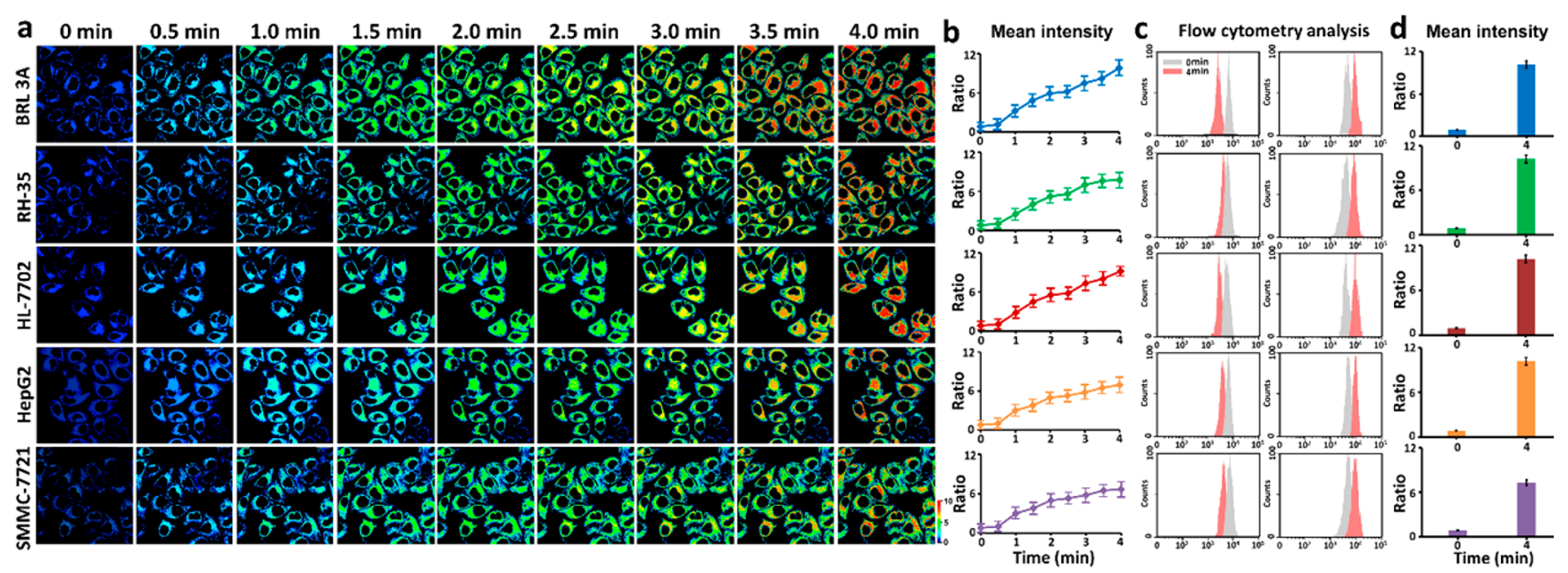

Figure 2. Quantitative application of Mito-diNO ${ }_{2}$ to endogenous Sec generation in living BRL-3A, BH-35, HL-7702, HepG2, and SMMC-7721 cells by confocal imaging and flow cytometry analysis. (a) Pseudocolor ratio images of endogenous Sec generation in BRL-3A, BH-35, HL-7702, HepG2, and SMMC-7721 cells at different time points: $0 \mathrm{~min}, 0.5 \mathrm{~min}, 1.0 \mathrm{~min}, 1.5 \mathrm{~min}, 2.0 \mathrm{~min}, 2.5 \mathrm{~min}, 3.0 \mathrm{~min}, 3.5 \mathrm{~min}$, and $4.0 \mathrm{~min}$ by confocal laser-scanning microscope with an objective lens $(\times 40)$. Fluorescence collection windows for channel $1,770-800 \mathrm{~nm}\left(\lambda_{\mathrm{ex}}=730 \mathrm{~nm}\right) ; \operatorname{channel} 2,650-750 \mathrm{~nm}\left(\lambda_{\mathrm{ex}}=\right.$ $635 \mathrm{~nm}$ ). (b) Plots of average ratio intensities of Mito-diNO $\mathrm{N}_{2}$ against time. Cell number $n=7$. (c) Flow cytometry analysis and (d) corresponding mean ratio intensities at time points: 0 and $4.0 \mathrm{~min}$. The experiments were repeated three times and the data were shown as mean ( \pm s.d.).

liver. Isoflurane was used as the anesthetic throughout the process.

Synthesis and Characterization of Probe. As shown in Scheme S1, compound $\mathbf{2}$ was synthesized by compound $\mathbf{3}$ and $\mathbf{4}$, which has been previously synthesized by our group. ${ }^{44}$ The compound $2(0.1 \mathrm{mmol}, 100 \mathrm{mg})$ was added in a solution of $\mathrm{Et}_{3} \mathrm{~N}$ $(0.1 \mathrm{mmol}, 10.1 \mathrm{mg})$ and $\mathrm{CH}_{2} \mathrm{Cl}_{2}(5 \mathrm{~mL})$ under $\mathrm{Ar}$ atmosphere. $^{32}$ 2,4-Dinitrobenzenesulfonyl chloride (0.12 mmol, $31.9 \mathrm{mg}$ ) in $6 \mathrm{~mL}$ of $\mathrm{CH}_{2} \mathrm{Cl}_{2}$ was slowly added to the above mixture. The resulting solution was stirred at room temperature for overnight. After the reaction completed, the mixture was extracted with $\mathrm{CH}_{2} \mathrm{Cl}_{2}$. Then the organic phase was desiccated with dry $\mathrm{Na}_{2} \mathrm{SO}_{4}$, the organic phase $\left(\mathrm{CH}_{2} \mathrm{Cl}_{2}\right)$ was concentrated. Purification by silica gel column chromatography (200-300 mesh) with gradient eluent $\mathrm{CH}_{3} \mathrm{OH}$ and $\mathrm{CH}_{2} \mathrm{Cl}_{2}$ $(0: 100-15: 85, \mathrm{v} / \mathrm{v})$ to obtain green solid (compound 1$).{ }^{1} \mathrm{H}$ NMR $\left(500 \mathrm{MHz}, \mathrm{CDCl}_{3}-d_{1}\right) \delta(\mathrm{ppm}): 8.63-8.60(\mathrm{~m}, 2 \mathrm{H})$, 8.55-8.49 (m, 1H), 8.19-8.18 (m, 1H), 7.99-7.70 (m, 22H), 7.53-7.46 (m, 1H), 7.24-7.20 (m, 2H), 7.19-7.06 (m, 1H), 7.88-7.80 (m, 1H), 5.81-5.78 (d, 2H), $5.77(\mathrm{~s}, 1 \mathrm{H}), 5.70(\mathrm{~s}$, $1 \mathrm{H}), 5.18(\mathrm{~s}, 2 \mathrm{H}), 4.91-4.89(\mathrm{t}, 2 \mathrm{H}), 4.70-4.66(\mathrm{q}, 2 \mathrm{H}), 4.42-$ $3.38(\mathrm{t}, 2 \mathrm{H}), 4.13-4.09$ (q, 2H), $3.98(\mathrm{~s}, 3 \mathrm{H}), 3.10-3.06(\mathrm{~m}$,
$1 \mathrm{H}), 2.45-2.36(\mathrm{~m}, 2 \mathrm{H}), 2.28-2.47(\mathrm{~m}, 2 \mathrm{H}), 1.72-1.52(\mathrm{~m}$, $10 \mathrm{H}), 1.35-1.20(\mathrm{~m}, 12 \mathrm{H}) .{ }^{13} \mathrm{C} \mathrm{NMR}\left(125 \mathrm{MHz}, \mathrm{CDCl}_{3}-d_{1}\right)$, $\delta(\mathrm{ppm}): 169.03,166.96,157.48,153.86,150.11,140.41,14.01$, $139.23,135.25,135.02,133.78,132.13,130.71,130.35,129.56$, $126.28,126.02,116.14,115.97,112.05,108.87,108.27,92.52$, $63.78,61.56,53.26,51.12,36.46,35.16,33.16,32.20,29.19$, $29.01,24.86,23.06,19.92,10.59,10.03$. GC-MS (API-ES): $m / z$ $\mathrm{C}_{72} \mathrm{H}_{75} \mathrm{~N}_{8} \mathrm{O}_{7} \mathrm{PS}^{2+}$ calcd 1226.5206; found, $[\mathrm{M}]^{2+} 613.2603$.

\section{RESULTS AND DISCUSSION}

Design and Synthesis of Mito-diNO ${ }_{2}$. To design a desirable fluorescent probe for the selective detection of selenol, we first examined the chemical properties of Sec. Although there exists quite distinct $\mathrm{p} K_{\mathrm{a}}$ between biothilos and bioselenols at physiological $\mathrm{pH}$ (7.40), for example, the $\mathrm{p} K_{\mathrm{a}}$ of $\mathrm{RSeH}$ is $\sim 5.2$, the $\mathrm{p} K_{\mathrm{a}}$ of cysteine (Cys) is $\sim 8.29$, and the $\mathrm{p} K_{\mathrm{a}}$ of glutathione (GSH) is $\sim 8.75,{ }^{45,46}$ the concentrations of thiols (GSH as representative) are at millimolar per liter $(\mathrm{mM})$ and the concentrations of selenol ( $\mathrm{Sec}$ as representative) are at micromole per liter $(\mu \mathrm{M})$ in living cells. ${ }^{47}$ The deprotonated anion $\left(\mathrm{RS}^{-}\right.$) may be much more than $\mathrm{RSe}^{-}$in living cells, which brings a big challenge for the selective detection of selenol in 


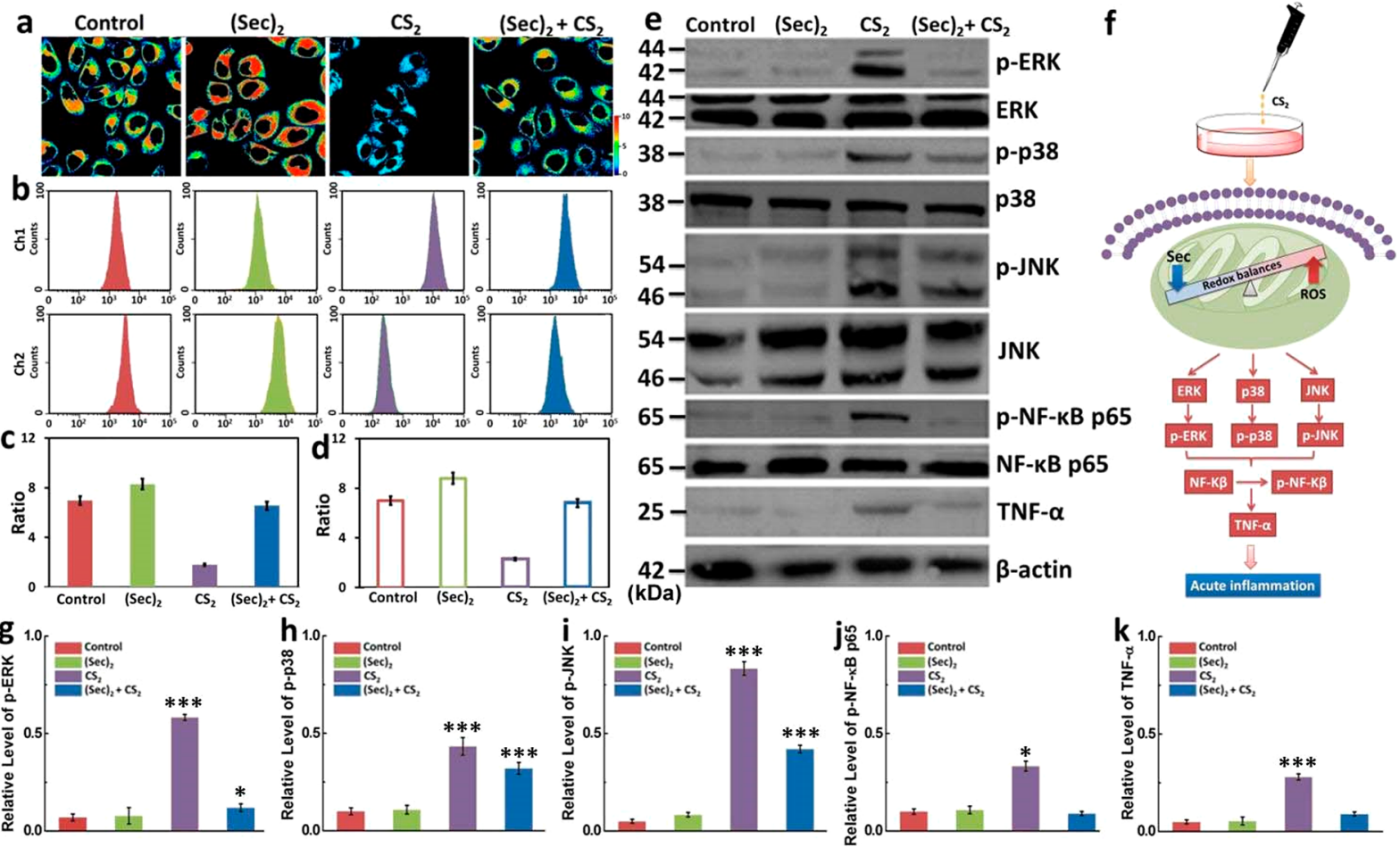

Figure 3. Evaluation the relationship between Sec concentration and mitochondrial related acute inflammation in SMMC-7721 cells. The cell were incubated with $10 \mu \mathrm{M} \mathrm{(Sec})_{2}$ for $24 \mathrm{~h}$, or $1 \mu \mathrm{M} \mathrm{CS}_{2}$ for $6 \mathrm{~h}$, or $\left.10 \mu \mathrm{M} \mathrm{(Sec}\right)_{2}$ for $24 \mathrm{~h}$ before the treatment of $1 \mu \mathrm{M} \mathrm{CS}_{2}$ for $6 \mathrm{~h}$, respectively. Mito-diNO 2 $(10 \mu \mathrm{M})$ was added for $4 \mathrm{~min}$ at $37^{\circ} \mathrm{C}$ before confocal imaging and flow cytometry analysis. (a) Pseudocolor ratio images of Sec concentration. (b) Flow cytometry analysis for quantitative application. (c) The ratio of mean ratio fluorescence intensities in part a. (d) The ratio of mean fluorescence intensities of two different detection channels in part b. (e) Western blotting analysis of p-ERK (phospho-ERK), p-p38 (phospho-p38), p-JNK (phospho-JNK), p-NF- $\kappa$ B p65 (phospho-NF- $\kappa$ B p65), and TNF- $\alpha$. Relative molecular mass of proteins (kDa) is displayed on the left. $\beta$-Actin was chosen as a loading control. (f) Scheme of $\mathrm{CS}_{2}$ induced mitochondrial related inflammation signal transduction pathways. (g) Densitometric analysis of the expression of p-ERK protein. (h) Densitometric analysis of the expression of p-p38 protein. (i) Densitometric analysis of the expression of p-JNK protein. (j) Densitometric analysis of the expression of p-NF- $\kappa$ B p65protein. (k) Densitometric analysis of the expression of TNF- $\alpha$ protein. The data were expressed as mean \pm s.d. $(n=7)$. To analyze the difference, one-way ANOVA and Bonferroni post-test were performed. $* P<0.05, * * P<0.01$, or $* * * P<0.001$ vs control group.

living system without the interferences from biothiols. Therefore, the choice of response moiety is pivotal. 2,4-Dinitrobenzenesulfonate ester has been developed to response biothiols in living cells. ${ }^{48}$ However, 2,4-dinitrobenzenesulfonamide, which exhibits a weaker electrophilic behavior, is a promising candidate for the detection of Sec, considering that selenols own stronger nucleophilic ability than thiols. ${ }^{28,49}$ The NIR heptamethine cyanine dye is selected as the fluorophore. The facile modulation of different electrondonating donors on cyanine fluorophore can lead to internal charge transfer (ICT) and then induce the emission spectrum blue/red shift, which result in a ratiometric fluorescent probe. ${ }^{50}$ Moreover, the substitution on the mesoposition of cyanine will result in a bulky steric hindrance, which can block the reaction with SePs and benefit for selectivity. The introduction of $\mathrm{PPh}_{3}{ }^{+}$moiety can lead probe Mito-diNO $\mathrm{N}_{2}$ to gathering in mitochondria. ${ }^{51,52}$ Now, the desirable NIR fluorescent probe Mito-diNO $\mathrm{N}_{2}$ was completely constructed for the imaging of Sec in living cell and in vivo. The molecular structure of our probe Mito-diNO $\mathrm{N}_{2}$ and its detection mechanism for Sec were described in Scheme 1. Sec would nucleophilic react with 2,4-dinitrobenzenesulfonamide, break the amide bond, and release the fluorophore Mito-Cy with obvious blue shift in emission spectral. The synthesis route of probe has been described in the Experimental Section.

Spectral Characteristics and Selectivity. The spectroscopic absorption and emission characteristics of the probe
Mito-diNO $\mathrm{N}_{2}$ were investigated at $37{ }^{\circ} \mathrm{C}$ in $10 \mathrm{mM}$ HEPES, $\mathrm{pH}$ 7.4. As shown in Figure S1a, the free probe exhibits the maximum absorption wavelength at $790 \mathrm{~nm}\left(\varepsilon_{790 \mathrm{~nm}}=1.51 \times 10^{4} \mathrm{M}^{-1}\right.$ $\left.\mathrm{cm}^{-1}\right)$. However, the maximum absorption wavelength shifted to $610 \mathrm{~nm}\left(\varepsilon_{610 \mathrm{~nm}}=3.36 \times 10^{4} \mathrm{M}^{-1} \mathrm{~cm}^{-1}\right)$, upon the addition of Sec. Also, the solution color changed from green to blue, concomitantly (Figure S1a). The fluorescence at $780 \mathrm{~nm}\left(\Phi_{780 \mathrm{~nm}}\right.$ $=0.03$ ) gradually decreased, and simultaneously, a new emission band at $744 \mathrm{~nm}\left(\Phi_{744 \mathrm{~nm}}=0.15\right)$ emerged and enhanced upon the addition of Sec (Figure S1b,c). The fluorescence intensity ratio $\left(F_{744 \mathrm{~nm}} / F_{780 \mathrm{~nm}}\right)$ was positively correlated with the Sec concentration (Figure S1d inset). Mito-diNO $\mathrm{NO}_{2}$ could selectively detect $\mathrm{Sec}$ without interference by other species (Figure S1e,f and Figure S2). The result in Figures S1-S3 demonstrated that our probe could be a potential tool for qualitative and quantitative analysis of Sec under physiological conditions.

Capability of Localization in Mitochondria. We planned to examine the possible application of $\mathbf{M i t o}-\mathrm{diNO}_{2}$ for the detection of Sec concentration fluctuation in living cells. To assess intracellular Sec concentration fluctuations, human epitheloid cervix carcinoma cell line (HeLa) was selected as the cell model. MTT assays were carried out to test the cytotoxicity of Mito-diNO $\mathrm{NO}_{2}$ prior to cell tests. The cells viability showed high values (Figures S4 and S6), indicating that probe Mito-diNO $\mathrm{N}_{2}$ has low cytotoxicity to cultured cells. All the HeLa cells were prestained with Mito-diNO $(10 \mu \mathrm{M}, 2 \mathrm{~min})$ at $37^{\circ} \mathrm{C}$ 
before imaging (Figure 1). The fluorescence images in channel 1 $(\mathrm{ch} 1,785 \pm 15) \mathrm{nm}$ and channel $2(\mathrm{ch} 2,700 \pm 50) \mathrm{nm}$ were excited by 730 and $635 \mathrm{~nm}$, respectively. The ratiometric images were obtained by the ratio fluorescence emission intensity of channel 2 vs channel 1. The fluorescence image of Mito-diNO in channel 1 was displayed in Figure 1. When the probe captured the intracellular Sec, fluorescence in channel 2 were emitted. Costaining experiments were carried out to verify the mitochondrial location potential of Mito-diNO $\mathrm{N}_{2}$. We selected commercial mitochondrial dye (Rhodamine 123) and nucleus dye (Hochest 33342 ) to detect mitochondrial targeting ability of $\mathbf{M i t o}-\mathbf{d i N O}_{2}$ in HeLa cells. As shown in Figure S7b, the cells were incubated with Rhodamine $123(1 \mu \mathrm{g} / \mathrm{mL}, 15 \mathrm{~min})$, and the images were collected through green channel $\left(\lambda_{\mathrm{ex}}=515 \mathrm{~nm}, \lambda_{\mathrm{em}}=575 \pm 25\right.$ $\mathrm{nm})$. Also, the cells were stained with Hochest $33342(1 \mu \mathrm{g} / \mathrm{mL}$, $30 \mathrm{~min})$ and the images were acquired through the blue channel $\left(\lambda_{\mathrm{ex}}=405 \mathrm{~nm}, \lambda_{\mathrm{em}}=450 \pm 30 \mathrm{~nm}\right.$ ) (displayed in Figure S7c). The merged images of red and blue channel exhibited no overlap between Mito-diNO ${ }_{2}$ and the nucleus dye Hochest 33342. While in the merged images of the red and green channel, the probe Mito-diNO $\mathrm{N}_{2}$ showed an excellent anastomosis with Rhodamine 123. The intensity distribution of Mito- $\mathrm{diNO}_{2}$ and rhodamine 123 exhibited a high correlated plot with a high Pearsons's coefficient $\mathrm{Rr}=0.995$. The intensity profiles of the white arrow regions of interest across HeLa (merge of red, green, and blue channels) exhibited in full synchrony. The above results showed that Mito-diNO $\mathrm{N}_{2}$ could stain mitochondria $\mathrm{Sec}$ with high selectivity in living cells.

Quantification of Sec in Living Cells. To evaluate the potential utility of Mito-diNO $\mathrm{Nor}_{2}$ qualitative and quantitative analysis of mitochondrial Sec, rat liver cell line (BRL 3A), rat hepatoma cell line (RH-35), human normal liver cell line (HL7702), human hepatocellular liver carcinoma cell line (HepG2), and human hepatocellular carcinoma cell line (SMMC-7721) were selected as test models. As shown in Figure 2a, the ratio fluorescence intensities increased during 0-4.0 min in BRL 3A, RH-3, HL-7702, HepG2, and SMMC-7721 cells. However, the mean ratio fluorescence intensities in the five different cell lines are distinct (Figure $2 \mathrm{~b}$ ), which illustrated that different cell lines contained different levels of Sec. We selected the time point at 4.0 min to access the Sec concentrations in the five types of cells.

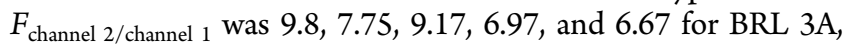
RH-3, HL-7702, HepG2, and SMMC-7721 cells, respectively. Based on the equation in Figure S1d, the Sec concentrations were determined as $4.30 \pm 0.11 \mu \mathrm{M}, 3.42 \pm 0.16 \mu \mathrm{M}, 4.03 \pm 0.30 \mu \mathrm{M}$, $3.08 \pm 0.40 \mu \mathrm{M}$, and $2.95 \pm 0.22 \mu \mathrm{M}$, correspondingly. The flow cytometry analysis was carried out at time points of 0 and $4.0 \mathrm{~min}$ (Figure 2c,d). The concentrations of Sec in BRL 3A, RH-3, HL7702, HepG2, and SMMC-7721 were determined as $4.37 \pm 0.15$ $\mu \mathrm{M}, 3.48 \pm 0.18 \mu \mathrm{M}, 4.13 \pm 0.20 \mu \mathrm{M}, 3.11 \pm 0.30 \mu \mathrm{M}$, and 2.98 $\pm 0.12 \mu \mathrm{M}$, respectively (Figure $2 \mathrm{e}$ ). The results obtained from ratio images and flow cytometry were well consistent, which confirmed the quantitative application of our probe Mito-diNO in living cells.

Protective Effects of Sec on $\mathrm{CS}_{2}$ Induced Mitochondrial Inflammation. Since our probe had been successfully applied to quantify endogenous Sec concentration in mitochondria, we tried to evaluate the protective effect of $\mathrm{Sec}$ in $\mathrm{CS}_{2}$ induced mitochondrial related inflammation. $(\mathrm{Sec})_{2}$ is reported as a $\mathrm{Sec}$ donor to protect cells from cell inflammation injury, which can promote Sec generation in living cells. ${ }^{37}$ As shown in Figure 3a, the treatment of $10 \mu \mathrm{M}(\mathrm{Sec})_{2}$ for $24 \mathrm{~h}$ showed strong ratio fluorescent signal, which implied the increased Sec concentration in mitochondria. The next group was treated with $1 \mu \mathrm{M} \mathrm{CS}_{2}$ for 6 $\mathrm{h}$ before imaging. Also, the addition of $\mathrm{CS}_{2}$ reduced the ratio fluorescent signal in Figure $3 \mathrm{a}$, demonstrating the decreased mitochondrial Sec level. The last group was pretreated with 10 $\mu \mathrm{M}(\mathrm{Sec})_{2}$ for $24 \mathrm{~h}$ before the addition of $1 \mu \mathrm{M} \mathrm{CS}_{2}$ for $6 \mathrm{~h}$. The ratio intensity was higher than the $\mathrm{CS}_{2}$ treated group. The results indicated that the pretreatment of $(\mathrm{Sec})_{2}$ could effectively prevent mitochondrial Sec decrease. The results obtained from confocal imaging (Figure 3a,c) were well consistent with flow cytometry analysis (Figure $3 \mathrm{~b}, \mathrm{~d}$ ). The results demonstrated that our probe could detect the mitochondrial Sec concentration changes.

The decrease of Sec concentration disturbed the redox balance and then may activate mitochondrial inflammatory response. Therefore, we further investigated $\mathrm{CS}_{2}$ induced mitochondrial inflammatory signaling pathway. Mitogen-activated protein kinases (MAPKs) are composed of a family of protein kinases which function and regulate a vast array of physiological processes, including inflammation. ${ }^{53}$ The MAPKs are regulated by a characteristic phosphorelay system in which a series of protein kinases phosphorylate and activate one another. ${ }^{54}$ Oxidative stress and pro-inflammatory factors can induce the activation and phosphorylation of extracellular regulated protein kinases (ERK), c-Jun N-terminal kinase (JNK), and p38. ${ }^{54}$ As shown in Figure 3e,g, the addition of $\mathrm{CS}_{2}$ activated the ERK phosphorylation, while the pretreatment of $(\mathrm{Sec})_{2}$ effectively inhibited the ERK phosphorylation. As shown in Figure 3e,h,i, the expressions of p-p38 and p-JNK were consistent with the expression levels of $\mathrm{p}$-ERK. The activation of ERK, JNK, and p38 will further stimulate the phosphorylation of nuclear factor kappa $\mathrm{B}(\mathrm{NF}-\kappa \mathrm{B}) .{ }^{55}$ As shown in Figure $3 \mathrm{e}, \mathrm{j}$, the addition of $\mathrm{CS}_{2}$ upregulated the expression of $\mathrm{p}-\mathrm{NF}-\kappa \mathrm{B}$ p 65 . However, the cells preincubated with $(\mathrm{Sec})_{2}$ before treatment with $\mathrm{CS}_{2}$ show a lower level of p-NF- $\kappa \mathrm{B}$ p65 expression. The induction of NF- $\kappa \mathrm{B}$ could enhance the secretion of tumor necrosis factor- $\alpha$ (TNF- $\alpha$ ), which would further induce acute inflammation. As shown in Figure $3 \mathrm{e}, \mathrm{k}$, the expression of pro-inflammatory cytokines TNF$\alpha$ was higher in the $\mathrm{CS}_{2}$ treatment group and the levels of TNF- $\alpha$ expression were negatively correlated with the concentrations of Sec. The results demonstrated that $\mathrm{CS}_{2}$ could deplete the concentrations of Sec and disturb the redox homeostasis of mitochondrion, then induce the phosphorylation of ERK, p38, and JNK (Figure 3f). The phosphorylation of the MAPKs activated NF- $\kappa \mathrm{B}$ p 65 and then induced the secretion of proinflammatory cytokines TNF- $\alpha$, which would cause acute inflammation. The result demonstrated that our probe could be used to potentially indicate the changes of Sec concentration in $\mathrm{CS}_{2}$-induced mitochondrial related acute inflammation.

Evaluation of Sec Protective Effects on $\mathrm{CS}_{2}$ Induced Acute and Chronic Hepatitis Mice Models. We next employed our probe to evaluate the protective effects of Sec on $\mathrm{CS}_{2}$ induced acute and chronic hepatitis mice models. The esatablishment of the acute and chronic hepatitis mice models were shown in Figure 4. Acute hepatitis mice model in group b, $\mathbf{c}$, d, and e were induced by i.p. injection of $\mathrm{CS}_{2}(0.6 \mathrm{~mL} / \mathrm{kg}, 50 \% \mathrm{v} /$ $\mathrm{v}$ in arachis oil) for $6,12,18$, and $24 \mathrm{~h}$, respectively. Also, the chronic inflammation mice models in groups $\mathbf{f}, \mathbf{g}, \mathbf{h}$, and $\mathbf{i}$ were established by inhaling $5 \% \mathrm{CS}_{2}$ (at air flow rate with $40 \mathrm{~mL} / \mathrm{min}$ for $1 \mathrm{~h}, \mathrm{qd}$ ) for 1 month, 2 months, 3 months, and 4 months. The therapy groups $(\mathbf{j}-\mathbf{n})$ for acute hepatitis were pretreated with $500 \mu \mathrm{g} / \mathrm{kg}(\mathrm{Sec})_{2}$ (i.p.) in PBS qd for 8 weeks throughout the experiment and suffered the same performance as acute hepatitis mice models for imaging. The therapy groups $(\mathbf{o}-\mathbf{r})$ for chronic 


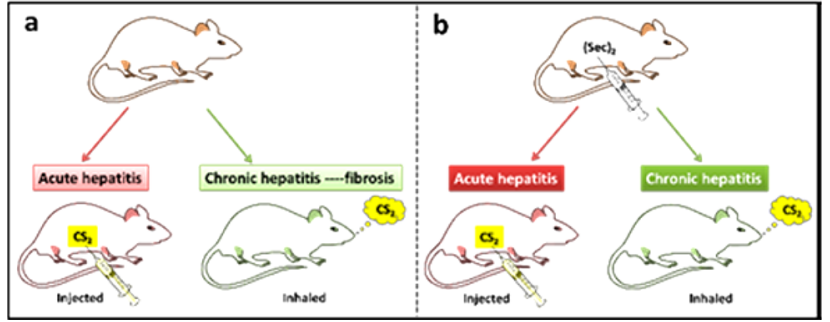

Figure 4. Illustration of the experimental protocol and the construction of $\mathrm{CS}_{2}$ induced acute/chronic hepatitis mice models and therapy mice models. (a) Acute hepatitis mice models were induced by i.p. injection of $\mathrm{CS}_{2}(0.6 \mathrm{~mL} / \mathrm{kg}, 50 \% \mathrm{v} / \mathrm{v}$ in arachis oil) for $6,12,18$, and $24 \mathrm{~h}$, respectively. Chronic hepatitis mice models were established by inhaling $5 \% \mathrm{CS}_{2}$ (at air flow rate with $40 \mathrm{~mL} / \mathrm{min}$ for $1 \mathrm{~h}, \mathrm{qd}$ ) for 1 month, 2 months, 3 months, and 4 months, respectively. (b) The therapy groups of acute hepatitis mice were pretreated with $500 \mu \mathrm{g} / \mathrm{kg}(\mathrm{Sec})_{2}$ (i.p.) in PBS qd for 8 weeks before i.p. injection of $\mathrm{CS}_{2}$. The therapy groups of chronic hepatitis mice were pretreated with $500 \mu \mathrm{g} / \mathrm{kg}(\mathrm{Sec})_{2}$ (i.p.) in PBS qd for 8 weeks before the inhalation of $\mathrm{CS}_{2}$. Also, $500 \mu \mathrm{g} / \mathrm{kg}(\mathrm{Sec})_{2}$ (i.p.) in PBS was continued to be given daily before the inhalation of $5 \%$ $\mathrm{CS}_{2}$ (at air flow rate with $40 \mathrm{~mL} / \mathrm{min}$ for $1 \mathrm{~h}, \mathrm{qd}$ ) for 1 month, 2 months, 3 months, and 4 months, respectively.

hepatitis mice were pretreated with $500 \mu \mathrm{g} / \mathrm{kg}(\mathrm{Sec})_{2}$ (i.p.) in PBS qd for 8 weeks before the inhalation of $\mathrm{CS}_{2}$. Also, $500 \mu \mathrm{g} / \mathrm{kg}$ $(\mathrm{Sec})_{2}$ (i.p.) in PBS was continued to be given daily before the inhalation of $5 \% \mathrm{CS}_{2}$ (at air flow rate with $40 \mathrm{~mL} / \mathrm{min}$ for $1 \mathrm{~h}, \mathrm{qd}$ ) for 1 month, 2 months, 3 months, and 4 months, respectively. The mice were given injection with the probe Mito-diNO ${ }_{2}(10$ $\mu \mathrm{M}, 50 \mu \mathrm{L}$, in 1:99 DMSO/saline, $\mathrm{v} / \mathrm{v}$ ) through the portal vein into liver to image the level changes of Sec. The representative fluorescent images (pseudocolor) in liver (Figure 5a) were acquired from channel 1 (with an excitation filter of $730 \mathrm{~nm}$, and an emission range of $780-800 \mathrm{~nm}$ ) and channel 2 (with an excitation filter of $600 \mathrm{~nm}$, and an emission range of $680-730$ $\mathrm{nm})$. The ratios of the mean number of photons channel $2 \mathrm{vs}$ channel 1 in Figure 5a were shown in Figure S10. As shown in Figure 5a and Figure S8, the ratio signal in group $\mathbf{b}$ was higher than that of group a, which demonstrated the increased generation of Sec during $6 \mathrm{~h}$ after $\mathrm{CS}_{2}$ i.p. injection. However, the ratio signals substantially decreased in group $\mathbf{c}, \mathbf{d}$, and $\mathbf{e}$, which indicated the decrease of Sec level along with the stimulation time. The results implied that in acute inflammatory stage, Sec concentration increased at $6 \mathrm{~h}$ and then decreased, probably resulting from the self-protection of organisms faced with acute hepatitis as we previously reported. ${ }^{37}$ Different from the groups of acute hepatitis, the concentrations of Sec in chronic hepatitis groups continued to decrease. As expected, the relatively stable ratio signals in the therapy groups indicated that the concentrations of Sec had been effectively supplemented (Movies I, II, III, and IV).

The degrees of liver injury of $\mathrm{CS}_{2}$ induced acute and chronic hepatitis mice models were confirmed via hematoxylin-eosin staining (H\&E) section, TdT-mediated dUTP nick end labeling (TUNEL) staining, Masson staining, and transmission electron microscopy (TEM). H\&E section was carried out to illustrate changes of pathological morphology in liver. The acute hepatitis mice models in groups $\mathbf{c}-\mathbf{e}$ showed more severe ballooning degeneration and cell death, while the chronic hepatitis mice models in groups $\mathbf{f}-\mathbf{i}$ displayed more serious hepatic fibrosis (Figure 5b). TdT-mediated dUTP nick end labeling (TUNEL) staining was carried out to indicate the cleavage of DNA and the cell apoptosis degrees. As shown in Figure 5c, heavy DNA cleavages were observed in group $\mathbf{c}-\mathbf{e}$. The degrees of DNA cleavage could be ordered: $\mathbf{b}<\mathbf{c}<\mathbf{d}<\mathbf{e}$. In groups $\mathbf{f}-\mathbf{i}$, DNA cleavage increaed along with the time of $\mathrm{CS}_{2}$ stimulation, and the degrees of DNA cleavage were ordered: $\mathbf{f}<\mathbf{g}<\mathbf{h}<\mathbf{i}$. Group $\mathbf{e}$ showed much more apoptosis than that in group $\mathbf{i}$, which resulted from high dose of $\mathrm{CS}_{2}$ stimulation in a short time. The degree of apoptosis was negatively correlated with the concentration of Sec. Masson staining was performed to evaluate the collagen deposition. In chronic hepatitis mice groups (groups $\mathbf{f}-\mathbf{i}$ ), much more collagen was stained than those in the acute hepatitis groups $\mathbf{b}-\mathbf{e}$ (Figure $5 \mathrm{~d}$ ). Transmission electron microscopy (TEM) was employed to evaluate the subcellular organelle damages. Cellular lipid globules and mitochondrial swelling were observed in the acute hepatitis mice groups $\mathbf{c}-\mathbf{e}$ (Figure 5e). However, in the chronic hepatitis mice groups, cellular lipid globules gradually disappeared. Meanwhile, mitochondria and endoplasmic reticulum suffered more serious swelling in groups $\mathbf{h}$ and $\mathbf{i}$ (Figure 5e). These pathological results demonstrated that the high dose exposure of $\mathrm{CS}_{2}$ in short-term led to severe acute hepatitis, and inhalation of $\mathrm{CS}_{2}$ in long-term resulted in chronic hepatitis. The results of therapy groups illustrated that Sec could effectively reduce the cytotoxicity and tissue damage caused by $\mathrm{CS}_{2}$ (Figure $5 \mathrm{~b}-\mathrm{e}$ ).

We next evaluated several serum markers to investigate the liver functions in $\mathrm{CS}_{2}$ induced acute/chronic hepatitis mice models. When hepatocytes were damaged, the levels of alanine aminotransferase (ALT) and aspartate transaminase (AST) would increase in serum. As shown in Figure 5f,g, the levels of ALT and AST increased with the degrees of acute hepatitis. They were kept relative high values during the chronic hepatitis process than the acute hepatitis process. Albumin (ALB) was a nutritional biomarker, which was related to liver function and consumption. As shown in Figure 5i, the mice in group i showed significant decrease than any other groups owing to the longterm liver dysfunction. The level of globulin (GLB) reflected the immune state of the organism. As shown in Figure 5h, GLB level increased in both acute and chronic hepatitis mice models, especially in the acute hepatitis mice model (Figure 5i). The result demonstrated strong immune response in acute inflammation period. Total bilirubin (TBIL) level was monitored to reveal the ability of liver eliminating bilirubin. The acute hepatitis groups showed an increase of TBIL level depending on the stimulation time, while the chronic hepatitis mice suffered from long-term high hyperbilirubinemia (Figure 5j). Serum alkaline phosphatase (ALP) levels, glutamyl transpeptidase (GGT) levels, and lactate dehydrogenase (LDH) levels implied liver metabolic function. The levels of ALP, GGT, and LDH showed quick increase (Figure $5 \mathrm{k}, \mathrm{l}, \mathrm{m}$ ), which illustrated the acute damage of inflammation in groups $\mathbf{b}-\mathbf{e}$. Also, the sustained exposure of $\mathrm{CS}_{2}$ in groups $\mathbf{f}-\mathbf{i}$ resulted in abnormal increases. For the therapy group $\mathbf{j}-\mathbf{r}$, the supplement of Sec could relieve the symptoms of hepatitis caused by $\mathrm{CS}_{2}$.

\section{CONCLUSION}

In summary, we develop a ratiometric NIR fluorescent probe for the quantification and evaluation of Sec-protective effect against $\mathrm{CS}_{2}$ induced cell and liver injury. The probe Mito-diNO ${ }_{2}$ is composed of three moieties: NIR heptamethine cyanine as the fluorescence transducer, 2,4-dinitrobenzenesulfonamide as the response unit, and $\mathrm{PPh}_{3}{ }^{+}$as the mitochondrial targeting unit. The probe Mito-diNO $\mathrm{N}_{2}$ can rapidly respond to Sec within $4 \mathrm{~min}$ without interferences from RSS, ROS, RNS, metal ions, and anions. The probe can well target in mitochondria and quantify 


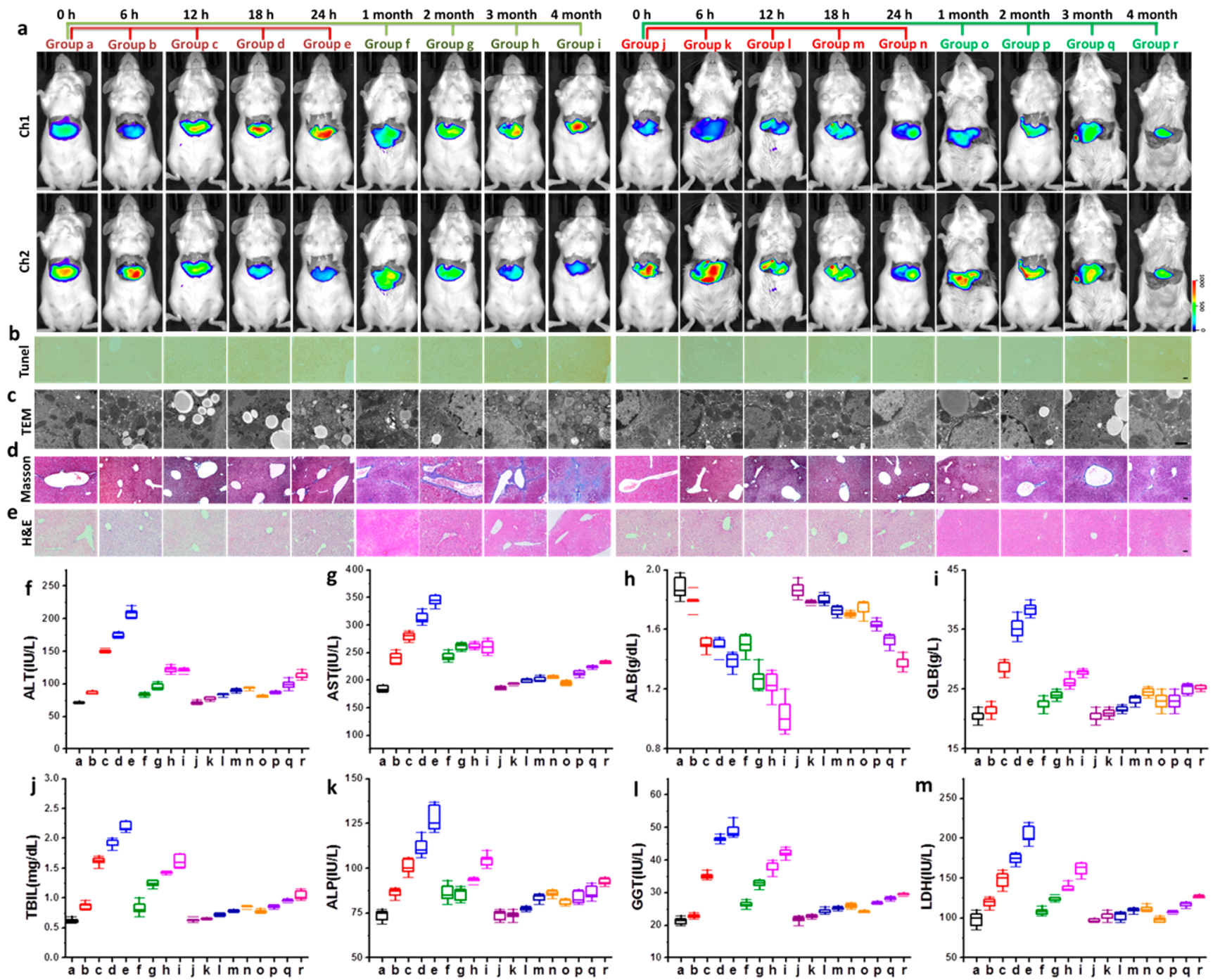

Figure 5. Evaluation of Sec in acute/chronic hepatitis mice models and therapy mice models. (a) In vivo imaging: Group a, control; Group $\mathbf{b}, \mathrm{CS}_{2}$ induced $6 \mathrm{~h}$ acute hepatitis BALB/c mice; Group c, $\mathrm{CS}_{2}$ induced $12 \mathrm{~h}$ acute hepatitis BALB/c mice; Group d, $\mathrm{CS}_{2}$ induced $18 \mathrm{~h}$ acute hepatitis BALB/c mice; Group e, $\mathrm{CS}_{2}$ induced $24 \mathrm{~h}$ acute hepatitis $\mathrm{BALB} / \mathrm{c}$ mice; Group $\mathrm{f}, \mathrm{CS}_{2}$ induced 1 month chronic hepatitis BALB/c mice; $\mathrm{Group}_{\mathrm{g}}$, CS 2 induced 2 months chronic hepatitis BALB/c mice; Group h, $\mathrm{CS}_{2}$ induced 3 months chronic hepatitis BALB/c mice; Group i, $\mathrm{CS}_{2}$ induced 4 months chronic hepatitis BALB/c mice; Groups $\mathbf{j}-\mathbf{n}$ were pretreated with $500 \mu \mathrm{g} / \mathrm{kg}(\mathrm{Sec})_{2}$ (i.p.) in PBS qd for 8 weeks before the same treatment of Groups a-i. Groups o-r were pretreated with $500 \mu \mathrm{g} / \mathrm{kg}(\mathrm{Sec})_{2}$ (i.p.) in PBS qd for 8 weeks. Also, then $500 \mu \mathrm{g} / \mathrm{kg}(\mathrm{Sec})_{2}$ (i.p.) in PBS was continued to be given daily before the inhalation of $5 \% \mathrm{CS}_{2}$ (at air flow rate with $40 \mathrm{~mL} / \mathrm{min}$ for $1 \mathrm{~h}$, qd) for 1 month, 2 months, 3 months, and 4 months, respectively. The mice were given injection with the probe Mito-diNO $(10 \mu \mathrm{M}, 50 \mu \mathrm{L}$, in 1:99 DMSO/saline, v/v) through portal vein into liver for 15 min before imaging. (b) Regional TUNEL staining in the liver. Scale bar: $100 \mu \mathrm{m}$. (c) TEM micrographs of liver tissues. Scale bar: $1 \mu \mathrm{m}$. (d) Masson's stained slice of liver tissues. Scale bar: $100 \mu \mathrm{m}$. (e) H\&E stained liver tissues histopathology images. Scale bar: $100 \mu \mathrm{m}$. (f) Serum ALT levels, (g) serum AST levels, (h) serum ALB levels, (i) serum GLB levels, ( $j$ ) serum TBIL levels, (k) serum ALP levels, (l) serum GGT levels, and (m) serum LDH levels. The data were expressed as mean \pm s.d. of seven experiments.

the Sec concentrations in BRL 3A, RH-35, HL-7702, HepG2, and SMMC-7721 cell lines. The probe has been successfully applied to detect the Sec concentration changes in $\mathrm{CS}_{2}$ induced mitochondrial related acute inflammation. The results illustrate that $\mathrm{Sec}$ is important to protect cells from inflammation. The utilization of Mito-diNO $\mathrm{NO}_{2}$ to evaluate $\mathrm{CS}_{2}$ induced Sec concentration fluctuation in acute and chronic hepatitis mice models further reveals the protective effects of Sec. We hope that our probe can be used as a potential chemical tool in accurate diagnosis and treatment of $\mathrm{CS}_{2}$ exposure.

\section{ASSOCIATED CONTENT}

\section{Supporting Information}

The Supporting Information is available free of charge on the ACS Publications website at DOI: 10.1021/acs.analchem.8b01306.

Movie I, acute hepatitis (AVI)

Movie II, chronic hepatitis (AVI)

Movie III, Sec therapy acute hepatitis (AVI)

Movie IV, Sec therapy chronic hepatitis (AVI)

Original spectra $\left({ }^{1} \mathrm{H} \mathrm{NMR},{ }^{13} \mathrm{C} \mathrm{NMR}\right.$, and HRMS), spectral properties of the probe, and more experimental materials and details (PDF) 


\section{AUTHOR INFORMATION}

\section{Corresponding Authors}

*E-mail: fbyu@yic.ac.cn.

*E-mail: 1xchen@yic.ac.cn.

\section{ORCID}

Fabiao Yu: 0000-0003-0073-6299

Lingxin Chen: 0000-0002-3764-3515

Notes

The authors declare no competing financial interest.

\section{ACKNOWLEDGMENTS}

We thank the National Nature Science Foundation of China (Grants 21775162, 21575159, 41776110, and 21405172), the program of Youth Innovation Promotion Association, CAS (Grant 2015170), State Key Laboratory of Environmental Chemistry and Ecotoxicology, Research Center for EcoEnvironmental Sciences, CAS (Grant KF2016-22), and the Instrument Developing Project of the Chinese Academy of Sciences (Grant YZ201662).

\section{REFERENCES}

(1) Hatfield, D. L.; Tsuji, P. A.; Carlson, B. A.; Gladyshev, V. N. Trends Biochem. Sci. 2014, 39, 112-120.

(2) Muttenthaler, M.; Alewood, P. F. J. Pept. Sci. 2008, 14, 1223-1239.

(3) Hatfield, D. L.; Berry, M. J.; Gladyshev, V. N. Selenioum: Its Molecular Biology and Role in Human Health; Kluver Academic Publishers: Norwell, MA, 2001.

(4) Papp, L. V.; Lu, J.; Holmgren, A.; Khanna, K. K. Antioxid. Redox Signaling 2007, 9, 775-806.

(5) Arnér, E. S.; Holmgren, A. Eur. J. Biochem. 2000, 267, 6102-6109.

(6) Lu, J.; Holmgren, A. J. Biol. Chem. 2009, 284, 723-727.

(7) Schmidt, R. L.; Simonović, M. Croat. Med. J. 2012, 53, 535-550.

(8) Li, F.; Lutz, P. B.; Pepelyayeva, Y.; Arnér, E. S.; Bayse, C. A.; Rozovsky, S. Proc. Natl. Acad. Sci. U. S. A. 2014, 111, 6976-6981.

(9) Palikaras, K.; Tavernarakis, N. Exp. Gerontol. 2014, 56, 182-188.

(10) López-Armada, M. J.; Riveiro-Naveira, R. R.; García, C. V.; Ares, M. N. V. Mitochondrion 2013, 13, 106-118.

(11) Pieczenik, S. R.; Neustadt, J. Exp. Mol. Pathol. 2007, 83, 84-92.

(12) DeMartino, A. W.; Zigler, D. F.; Fukuto, J. M.; Ford, P. C. Chem. Soc. Rev. 2017, 46, 21-39.

(13) Magos, L. Ann. Occup. Hyg. 1972, 15, 303-309.

(14) Beauchamp, R. O., Jr; Bus, J. S.; Popp, J. A.; Boreiko, C. J.; Goldberg, L. Crit. Rev. Toxicol. 1983, 11, 169-278.

(15) Killa, H. M.; Rabenstein, D. L. Anal. Chem. 1988, 60, 2283-2287.

(16) Rabenstein, D. L.; Reid, R. S.; Yamashita, G.; Tan, K. S.; Arnold, A.

P. Anal. Chem. 1986, 58, 1266-1269.

(17) B’Hymer, C.; Caruso, J. A. J. Chromatogr. A 2006, 1114, 1-20.

(18) Yoon, J. Coord. Chem. Rev. 2018, 354, 1.

(19) Gao, M.; Yu, F.; Lv, C.; Choo, J.; Chen, L. Chem. Soc. Rev. 2017, 46, 2237-2271.

(20) Yin, J.; Hu, Y.; Yoon, J. Chem. Soc. Rev. 2015, 44, 4619-4644.

(21) Tang, Y.; Lee, D.; Wang, J.; Li, G.; Yu, J.; Lin, W. Chem. Soc. Rev. 2015, 44, 5003-5015.

(22) Kolanowski, J. L.; Liu, F.; New, E. J. Chem. Soc. Rev. 2018, 47, 195-208.

(23) Zhu, H.; Fan, J.; Du, J.; Peng, X. Acc. Chem. Res. 2016, 49, 21152126.

(24) Kim, H. J.; Heo, C. H.; Kim, H. M. J. Am. Chem. Soc. 2013, 135, 17969-17977.

(25) Park, S. J.; Lee, H. W.; Kim, H.; Kang, C.; Kim, H. M. Chem. Sci. 2016, 7, 3703-3709.

(26) Dai, C. G.; Wang, J. L.; Song, Q. H. J. Mater. Chem. B 2016, 4, 6726-6733.

(27) Li, M.; Feng, W.; Zhai, Q.; Feng, G. Biosens. Bioelectron. 2017, 87, 894-900.
(28) Maeda, H.; Katayama, K.; Matsuno, H. Angew. Chem., Int. Ed. 2006, 45, 1810-1813.

(29) Cheng, D.; Pan, Y.; Yin, B. C.; Yuan, L.; Zhang, X. B. Chin. Chem. Lett. 2017, 28, 1987-1990.

(30) Chen, H.; Dong, B.; Tang, Y.; Lin, W. Chem. - Eur. J. 2015, 21, 11696-11700.

(31) Sun, Q.; Yang, S. H.; Wu, L.; Dong, Q. J.; Yang, W. C. Anal. Chem. 2016, 88, 6084-6091.

(32) Zhang, B.; Ge, C.; Yao, J.; Liu, Y.; Xie, H.; Fang, J. J. Am. Chem. Soc. 2015, 137, 757-769.

(33) Feng, W.; Li, M.; Sun, Y.; Feng, G. Anal. Chem. 2017, 89, 61066112.

(34) Areti, S.; Verma, S. K.; Bellare, J.; Rao, C. P. Anal. Chem. 2016, 88, $7259-7267$.

(35) Kong, F.; Hu, B.; Gao, Y.; Xu, K.; Pan, X.; Huang, F.; Zheng, Q.; Chen, H.; Tang, B. Chem. Commun. 2015, 51, 3102-3105.

(36) Tian, Y.; Xin, F.; Gao, C.; Jing, J.; Zhang, X. J. Mater. Chem. B 2017, 5, 6890-6896.

(37) Han, X.; Song, X.; Yu, F.; Chen, L. Adv. Funct. Mater. 2017, 27, 1700769.

(38) Guo, Z.; Park, S.; Yoon, J.; Shin, I. Chem. Soc. Rev. 2014, 43, 1629.

(39) Yuan, L.; Lin, W.; Zheng, K.; He, L.; Huang, W. Chem. Soc. Rev. 2013, 42, 622-661.

(40) Yu, F.; Gao, M.; Li, M.; Chen, L. Biomaterials 2015, 63, 93-101.

(41) Lee, M. H.; Kim, J. S.; Sessler, J. L. Chem. Soc. Rev. 2015, 44, $4185-4191$

(42) Han, X.; Yu, F.; Song, X.; Chen, L. Chem. Sci. 2017, 8, 6991-7002.

(43) Bond, E. J.; Butler, W. H.; De Matteis, F.; Barnes, J. M. Br. J. Industr. Med. 1969, 26, 335-337.

(44) Han, X.; Wang, R.; Song, X.; Yu, F.; Lv, C.; Chen, L. Biomaterials 2018, 156, 134-146.

(45) Huber, R. E.; Criddle, R. S. Arch. Biochem. Biophys. 1967, 122, 164-173.

(46) Storkey, C.; Pattison, D. I.; Ignasiak, M. T.; Schiesserd, C. H.; Davies, M. J. Free Radical Biol. Med. 2015, 89, 1049-1056.

(47) Turell, L.; Radi, R.; Alvarez, B. Free Radical Biol. Med. 2013, 65, 244-253.

(48) Maeda, H.; Matsuno, H.; Ushida, M.; Katayama, K.; Saeki, K.; Itoh, N. Angew. Chem. 2005, 117, 2982-2985.

(49) Wu, D.; Chen, L.; Kwon, N.; Yoon, J. Chem. 2016, 1, 674-698.

(50) Han, X.; Yu, F.; Song, X.; Chen, L. Chem. Sci. 2016, 7, 5098-5107.

(51) Zielonka, J.; Joseph, J.; Sikora, A.; Hardy, M.; Ouari, O.; Vivar, J. V.; Cheng, G.; Lopez, M.; Kalyanaraman, B. Chem. Rev. 2017, 117, 10043-10120.

(52) Gao, M.; Wang, R.; Yu, F.; Chen, L. Biomaterials 2018, 160, 1-14.

(53) Robinson, M. J.; Cobb, M. H. Curr. Opin. Cell Biol. 1997, 9, 180186.

(54) Johnson, G. L.; Lapadat, R. Science 2002, 298, 1911-1912.

(55) Tak, P. P.; Firestein, G. S. J. Clin. Invest. 2001, 107, 7-11. 